\title{
Tsunami hazard assessment along Diba-Oman and Diba-Al-Emirates coasts
}

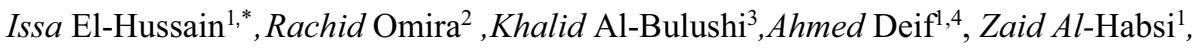 \\ Ghazi Al-Rawas ${ }^{1}$, Adel Mohamad ${ }^{1,4}$, Khalifa Al-Jabri ${ }^{1}$, Maria Ana Baptista ${ }^{5}$ \\ ${ }^{1}$ Earthquake Monitoring Center, Sultan Qaboos University, P.O. Box 50, Al-Khoudh, PC 123, \\ Muscat, Oman \\ elhussain@squ.edu.om, Tel. +(968) 24142642 Fax +(968) 24413137 \\ ${ }^{2}$ Instituto Português do Mar e da Atmosfera, Rua C do Aeroporto, 1749-077 Lisboa, Portugal \\ ${ }^{3}$ Department of Earth Science, United Arab Emirates University \\ ${ }^{4}$ National Research Institute of Astronomy and Geophysics, Helwan, Egypt \\ ${ }^{5}$ Instituto Superior de Engenharia de Lisboa, Instituto Politécnico de Lisboa, R. Conselheiro Emidio \\ Navarro, 1, 1959-007 Lisboa, Portugal
}

\begin{abstract}
Tsunami is among the most devastating natural hazards phenomenon responsible for significant loss of life and property throughout history. The Sultanate of Oman and United Arab Emirates are among the Indian Ocean countries that were subjected to one confirmed tsunami in November 27, 1945 due to an Mw 8.1 earthquake in Makran Subduction Zone. In this study, we present preliminary deterministic tsunami hazard assessment for the coasts of Diba Oman and Diba AlEmirates, which are located on the western coast of the Oman Sea. The tsunami vulnerability of these cities increases due to the construction of many critical infrastructures and urban concentration along their coasts. Therefore, tsunami hazard assessment is necessary to mitigate the risk on the socio-economic system and sustainable developments. The major known source of tsunamis able to impact both coasts of Oman and United Arab Emirates is the Makran Subduction Zone (MSZ) which extends for approximately $900 \mathrm{~km}$. The deterministic approach uses specific scenarios considering the maximum credible earthquakes occurring in the MSZ and computes the ensuing tsunami impact in the coasts of the study area. The maximum wave height graphs and inundation maps are obtained for tsunami scenarios caused by 8.8 earthquake magnitude in eastern MSZ and 8.2 magnitude from western MSZ. The Mw8.8 eastern MSZ causes a maximum inundation distance of 447 meters and a maximum flow depth of 1.37 meter. Maximum inundation distance larger than 420 meters occurs due to the Mw8.2 western MSZ scenario. For this scenario, numerical simulations show a maximum flow depth of about 2.34 meters.
\end{abstract}

\footnotetext{
*Corresponding author: elhussain@squ.edu.om
} 


\section{Introduction}

A tsunami is a series of water waves that propagate from the location of the tsunamigenic source toward the shore. The term tsunami can be referred to the water waves caused by rapid vertical displacement of the water column in open oceans or inland water bodies.Tsunamis can be severely destructive to the infrastructure, human life, and the economy of the coastal areas. They may inundate large onshore areas based upon the local bathymetry and topography. The hydrostatic and hydrodynamic forces associated with the tsunamis may damage structures in such coastal areas. The most frequent cause of tsunamis is large submarine earthquakes. Less frequently, tsunamis are generated by submarine landslides, by pyroclastic flows and caldera collapses during volcanic eruptions, by meteorite impacts, and by snow avalanches. These long-period tsunami waves can travel very far from the source without much attenuation. The waves decrease in velocity and increase in amplitude as they reach shallow water zones near the shore. The amplification of the wave depends on the local, near-shore bathymetry. The maximum ground elevation that the tsunami waves reach above a datum is defined as run-up.

Tsunamis generated in the Indian Ocean pose a great threat to all the countries of the region. Oman and United Arab Emirates (UAE) are among the affected countries. The main objective of this research study is to assess the tsunami hazard posed by the Probable Maximum Tsunami (PMT) at the coastal areas of Diba Oman and Diba UAE (Fig. 1) and to determine whether any protective measures are required.

\section{The study area and tsunamigenic source}

Tsunami hazard along the coast of Diba, Oman and UAE, is mainly due to the seismic activity at the Makran subduction zone, located circa 150 to $600 \mathrm{~km}$ east of the Diba coast. The tsunamigenic source region that has the potential to affect the coasts of Diba OmanUAE is delineated on the basis of historical earthquake records, tsunami data, and sea bathymetric data. The source mechanism and characteristics of the Probable Maximum Tsunami (PMT) are evaluated based on the maximum magnitude earthquake estimated by [1]. The established source parameters are then used to numerically model the tsunami caused by the PMT scenarios. The potential coastal inundation and run-ups maps are estimated for each PMT scenario. The potential tsunami impact on Diba Oman-UAE coasts (Fig. 1) is conducted utilizing Deterministic Tsunami Hazard Assessment approach. 


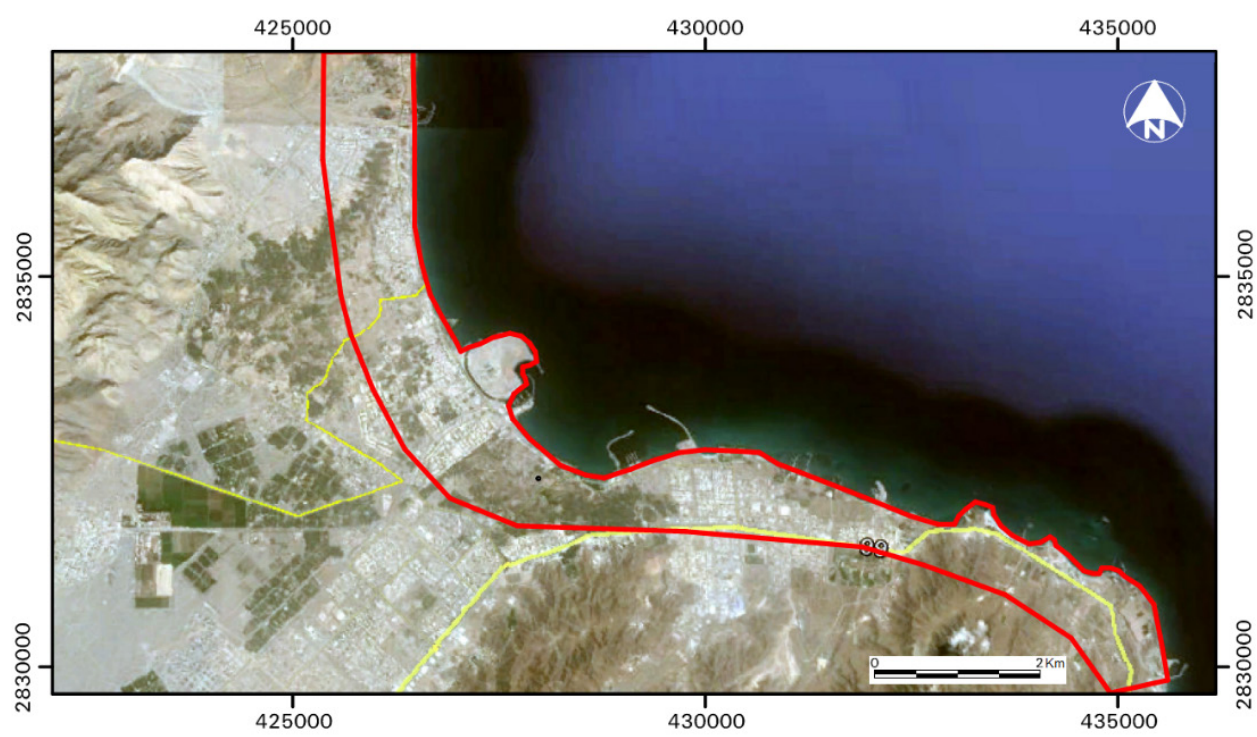

Fig. 1. Map show the Diba Oman and Diba Al Emirates coastal areas along the Sea of Oman.

\section{Historical tsunami records}

The primary tsunami threat to Diba Oman-UAE coastal area is from the MSZ located eastnortheast of the UAE coast. Although large earthquakes along the MSZ are infrequent, they have the potential to generate destructive tsunamis in the Northern Arabian Sea. Quick survey of the tsunami history in the Oman-UAE indicates that at least one confirmed tsunami might have struck their coasts in 1945. A great earthquake with moment magnitude 8.1 occurred off Makran coast of Pakistan, about $100 \mathrm{~km}$ south of Karachi in 1945. The earthquake generated a very destructive tsunami, which is reported to affect Pakistan, the western coast of India, Iran, UAE and Oman, killing hundreds of people and causing great destruction. A maximum run-up of $13 \mathrm{~m}$ is reported in Pakistan [2, 3]. The tsunami is recorded in Muscat but no details of damage were documented. The tsunami was generated along an active Makran subduction zone, which marks the boundary between the Arabian Plate and the stable Eurasian Plate. Therefore, it is anticipated that future tsunamis can be generated from large earthquakes along MSZ. All published articles in relation to tsunamis from the Makran fault are reviewed [1-12].

\section{Data collection and quality assurance}

Tsunami simulation results are strongly dependent on the accuracy and resolution of the Digital Elevation Model (DEM), and must ensure that the onshore and off-shore components of the potential flooding area are properly described in terms of vertical data. This is particularly important because the vertical references of topographic maps made onshore and nautical charts are often different. Therefore, the first step is the establishment and validation of a DEM from all available bathymetric datasets: local bathymetry around the coasts and navigation channel, regional bathymetry from available digital charts, and its validation, particularly with the direct inspection of the most sensitive locations. 
Tsunami simulation models use grids of different resolution for different stages of tsunami propagation because the onshore propagation (inundation stage) requires much higher resolution, to be able to correctly describe the target area (Fig. 2).

The original bathymetric set of data is prepared to be used in the numerical simulation by specifying: the region of interest, the desired grid resolution (i.e. the density of nodes present in the resulting grid). The compiled grid was checked and corrected for errors that may appear due to the interpolation process. For deep ocean tsunami simulation, GEBCO 30 second arc resolution gridded data were used [13].

Digitization of bathymetric regional charts and generation of near-shore bathymetric grid including the study area was performed. The fusion of high-resolution depth and height data requires a common definition for the vertical reference surface. The zero height contour line is, in general, obtained from the topographic data and is used as the boundary for land-sea transition (Fig. 3). Once this procedure is completed, depth and height data are merged subjected to the zero line constraint and carefully edited on the onshore-offshore envelope.

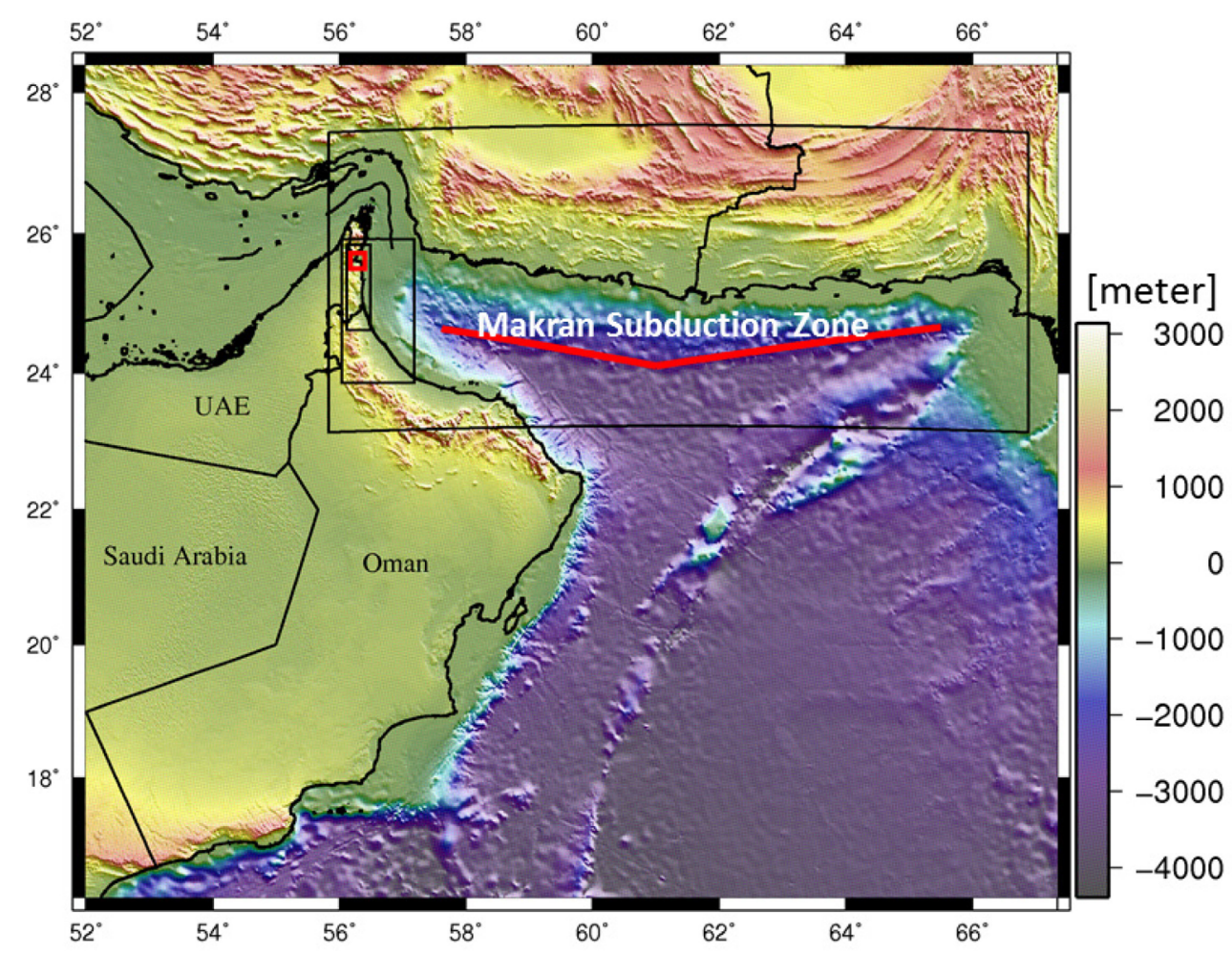

Fig. 2. DTM showing bathymetry and topography grid with four nesting grid levels used for Diba tsunami simulation with grid spacing of $3750 \mathrm{~m}, 750 \mathrm{~m}, 150 \mathrm{~m}$ and $30 \mathrm{~m}$ respectively. 


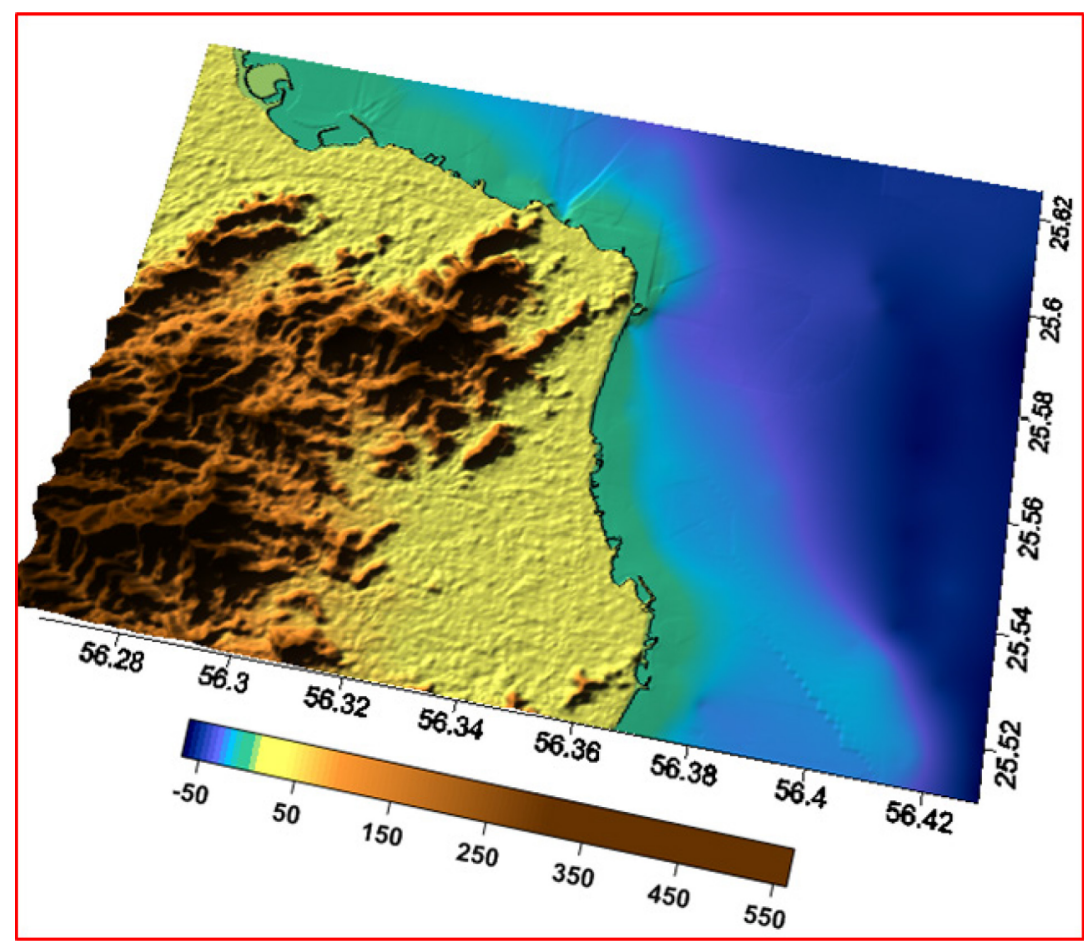

Fig. 3. A 3D view of level 4 grid 30m resolution for Diba UAE.

\section{Tsunami model implementation}

The numerical model used to simulate tsunami propagation and run-up is based on the Non-Linear Shallow Water equations, solved infinite differences scheme. Two of the implementations that have been widely used in previous studies are MOST [14] and COMCOT [e.g. 15]. Both models are able to simulate the generation, propagation, inundation, run-up and run-down, and have been benchmarked.

\section{Deterministic tsunami hazard assessment}

The methodology called Deterministic Tsunami Hazard Assessment (DTHA) is based upon the definition of tsunami scenarios. In this case, the different hazard maps result from a set of individual sources that may affect the target area. Based on available seismic information, two earthquakes, with several hundred years return period [1,9] representing worst case tsunami scenarios for Diba coasts are simulated Table 1. The impact of each individual scenario is presented in terms of maximum wave height, tsunami travel time, and maximum inundation distance. 
Table 1.Makran Subduction Zone Tsunamigenic Earthquake Scenarios.

\begin{tabular}{|l|l|l|l|l|l|l|l|l|}
\hline \multicolumn{2}{|l|}{ Makran Subduction Zone Scenarios } \\
\hline Scenario & MSZ & Length(km) & Width(km) & Slip(m) & Dip $\left(^{\circ}\right)$ & Strike( $^{\circ}$ ) & Rake( $^{\circ}$ ) & M \\
\hline One & Eastern & 461 & 110 & 11.1 & 7 & 263 & 90 & 8.8 \\
\hline Two & Western & 201 & 82 & 6 & 7 & 281 & 90 & 8.2 \\
\hline
\end{tabular}

\section{Results}

Numerical simulations of the tsunami propagation from the source area to the target area with onshore propagation (inundation) are conducted. The outputs of this task are grids and maps of tsunami travel time (Fig. 4), synthetic waveform tsunamis at specific points (virtual tide gage) along the target area (Fig. 5a and b), and maximum wave height (Fig. 6). Fig 4 is coarse grid map of bathymetry and topography with 30 second arch resolution with contours representing the tsunami travel times (TTT) in hours following the occurrence of Mw 8.8 earthquake event in Eastern Makran Subduction Zone. Fig 6 is the Tsunami hazard map showing the maximum inundation distances of 40 and $447 \mathrm{~m}$, the maximum flow depths of 1.37 and $1.26 \mathrm{~m}$, and the runup of 1.05 and $1.16 \mathrm{~m}$ for Diba Oman and Diba Al Emirates respectively, due to the Mw 8.8 scenario from eastern Makran Subduction Zone.

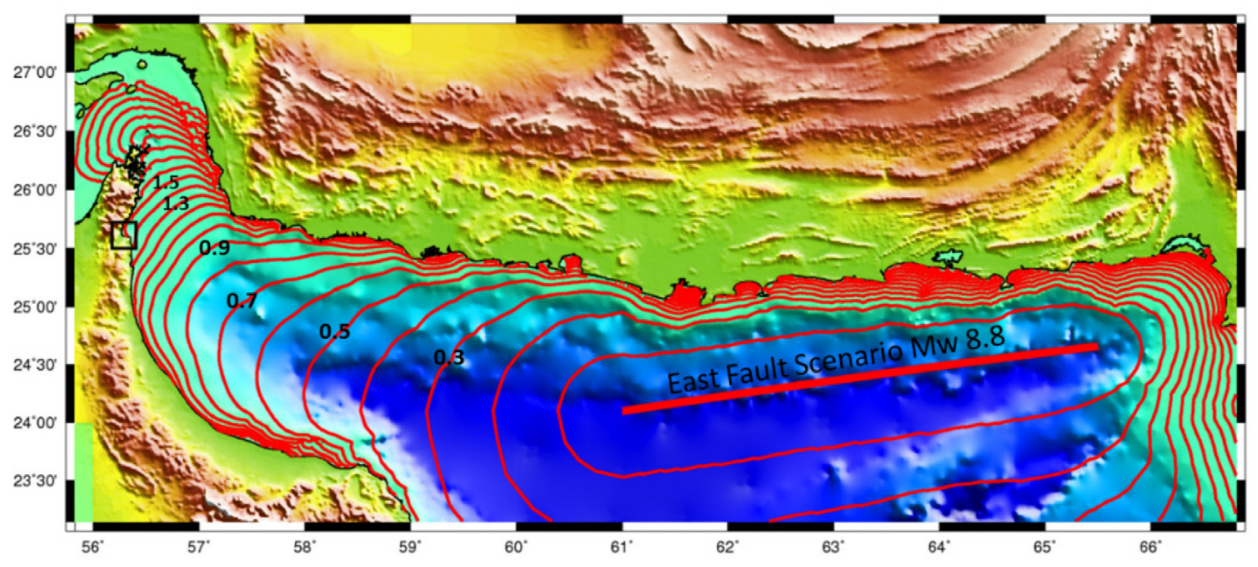

Fig. 4.Tsunami travel time in hours (red contours) for scenario one $\mathrm{M}_{\mathrm{w}} 8.8$, eastern MSZ. 


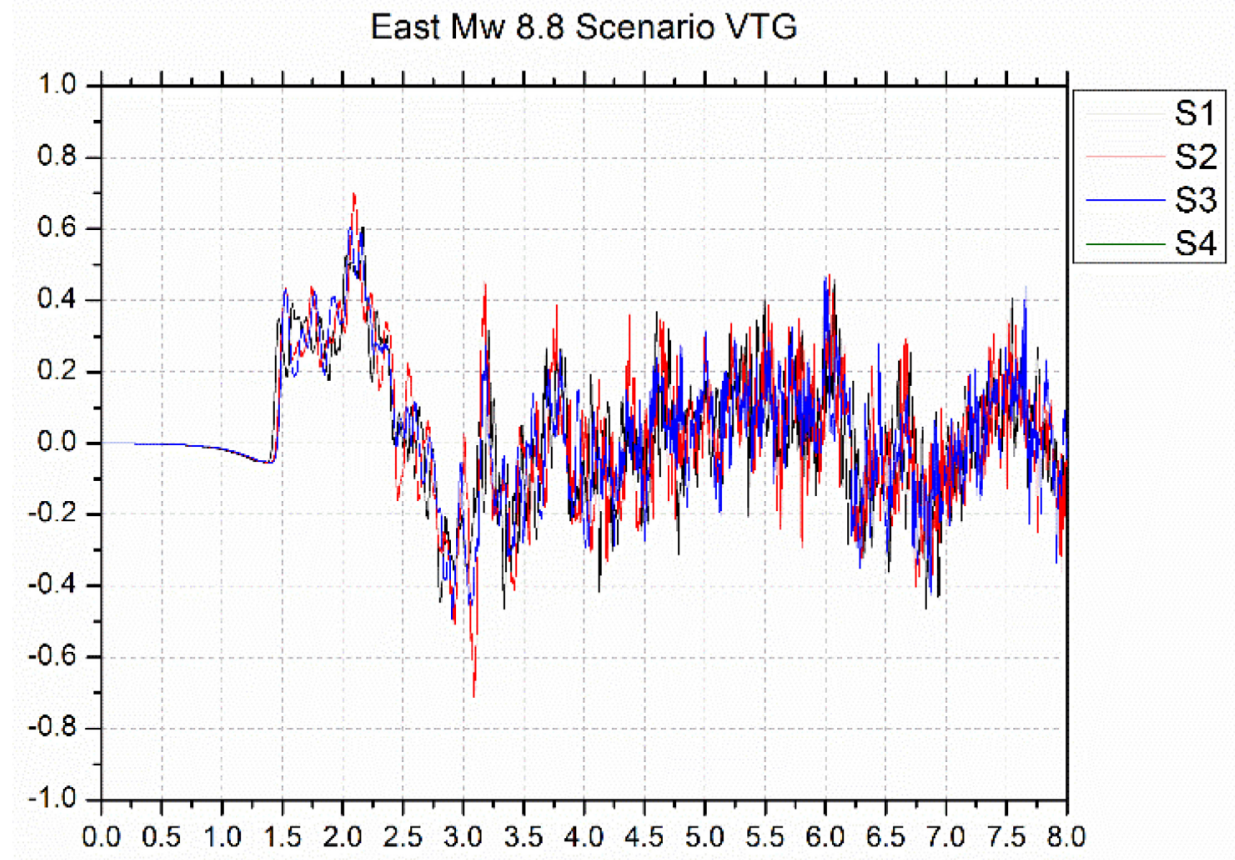

Fig. 5a. Synthetic waveforms at VTG from S1 to S4 (locations in Figure 6), maximum wave height of $0.8 \mathrm{~m}$.

East Mw 8.8 Scenario VTG

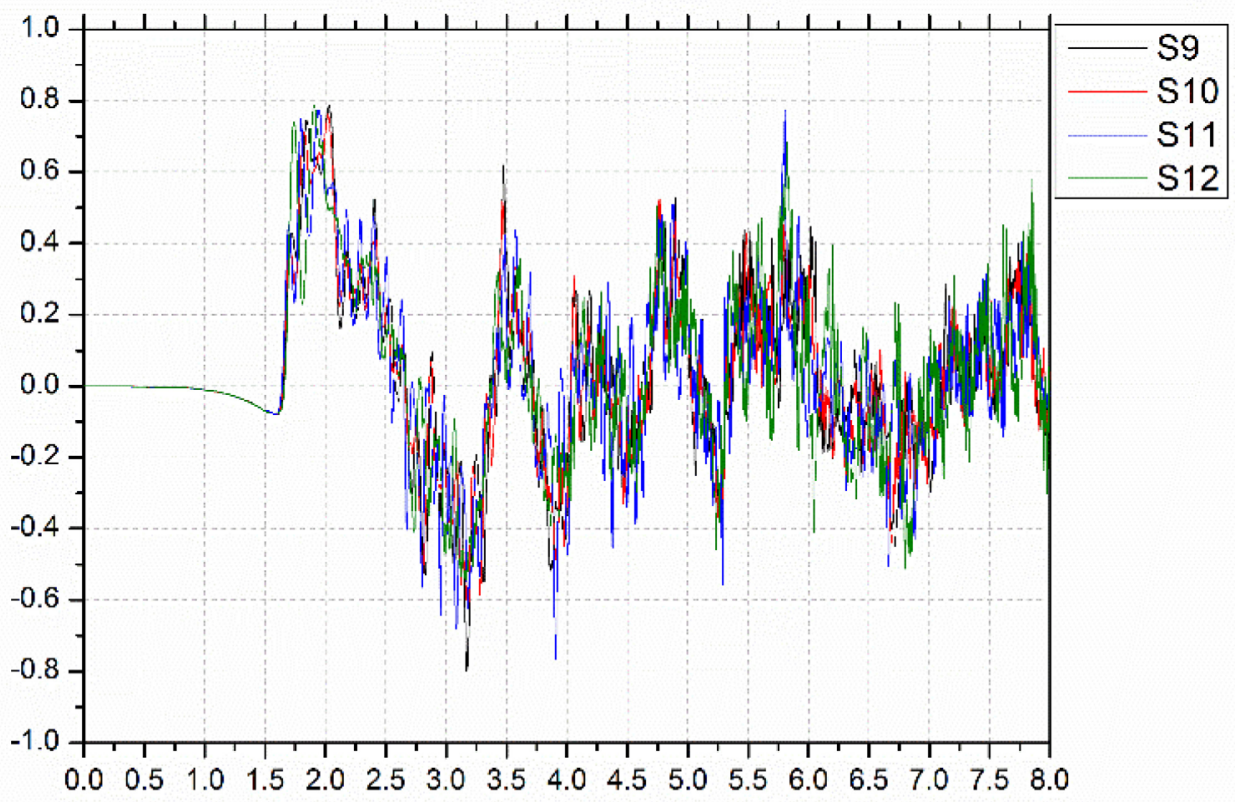

Fig. 5b. Synthetic waveforms at VTG from S9 to S12 (locations in Figure 6), maximum wave height of $0.8 \mathrm{~m}$. 


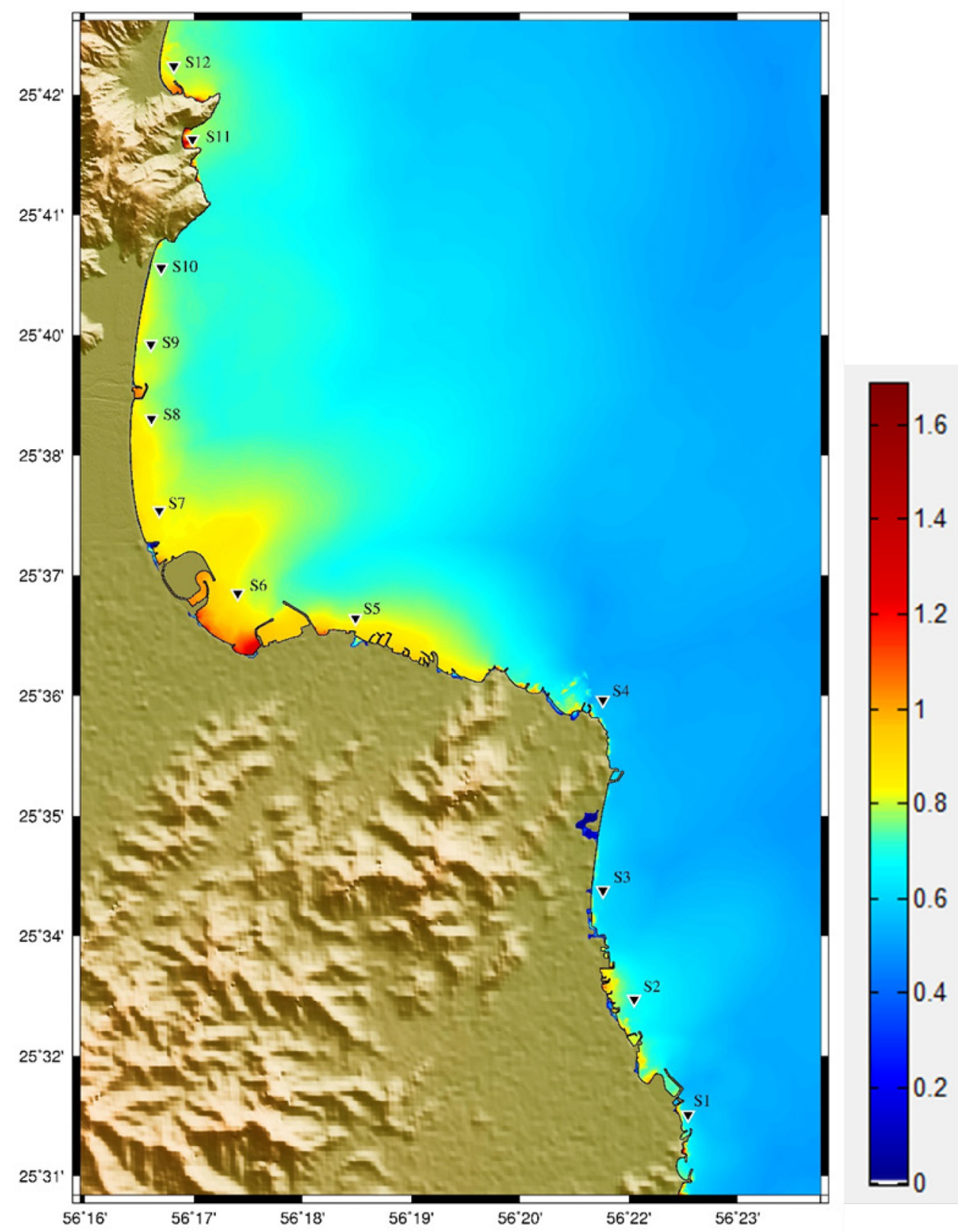

Fig. 6. Tsunami hazard map for Diba Oman with $5 \mathrm{~m}$ grid spacing representing maximum wave height and inundation in meters for Scenario One $\mathrm{M}_{\mathrm{w}} 8.8$.

Fig 7 is coarse grid map of bathymetry and topography with 30 -second arc resolution with contours representing TTT in hours following the occurrence of Mw 8.2 earthquake event in western Makran Subduction Zone. Figs 8a and b show the synthetic waveform of the tsunami at specific points (virtual tide gage) along the target area. Fig 9 is the tsunami hazard map showing the maximum inundation distances of 150 and $420 \mathrm{~m}$, the maximum flow depths of 2.18 and $2.34 \mathrm{~m}$, and runup of 2.42 and $2.57 \mathrm{~m}$ for Diba Oman and Diba Al Emirates respectively, due to the Mw 8.2 scenario from western Makran Subduction Zone. 


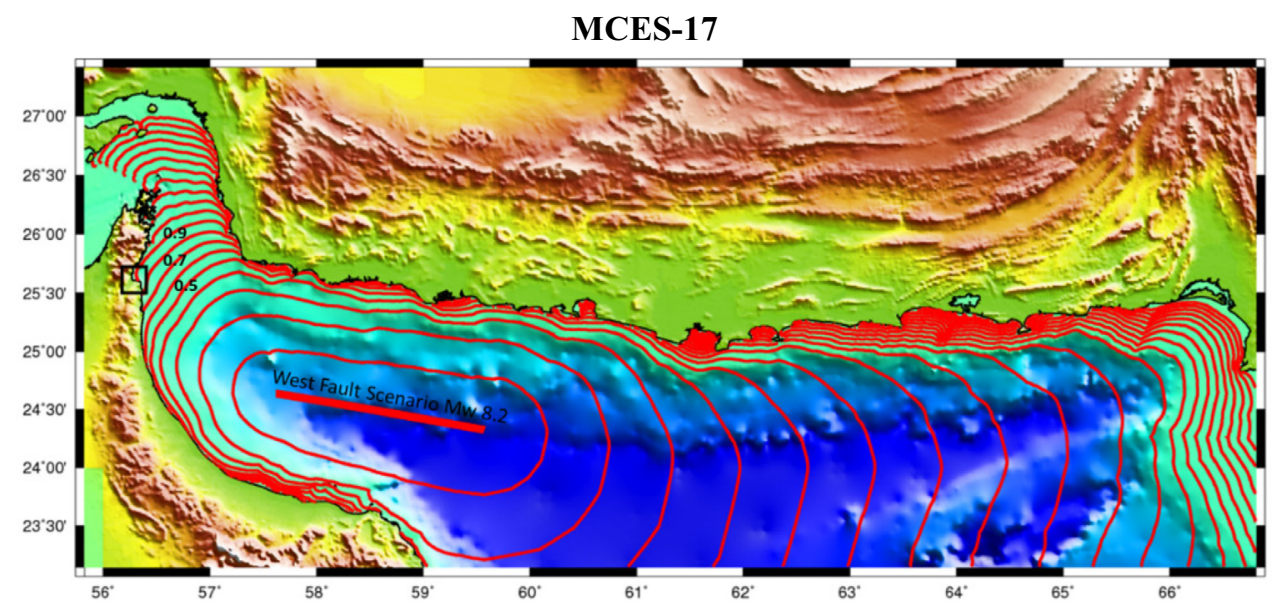

Fig. 7.Tsunami travel time in hours (red contours) for scenario two $\mathrm{M}_{\mathrm{w}} 8.2$, Western MSZ.

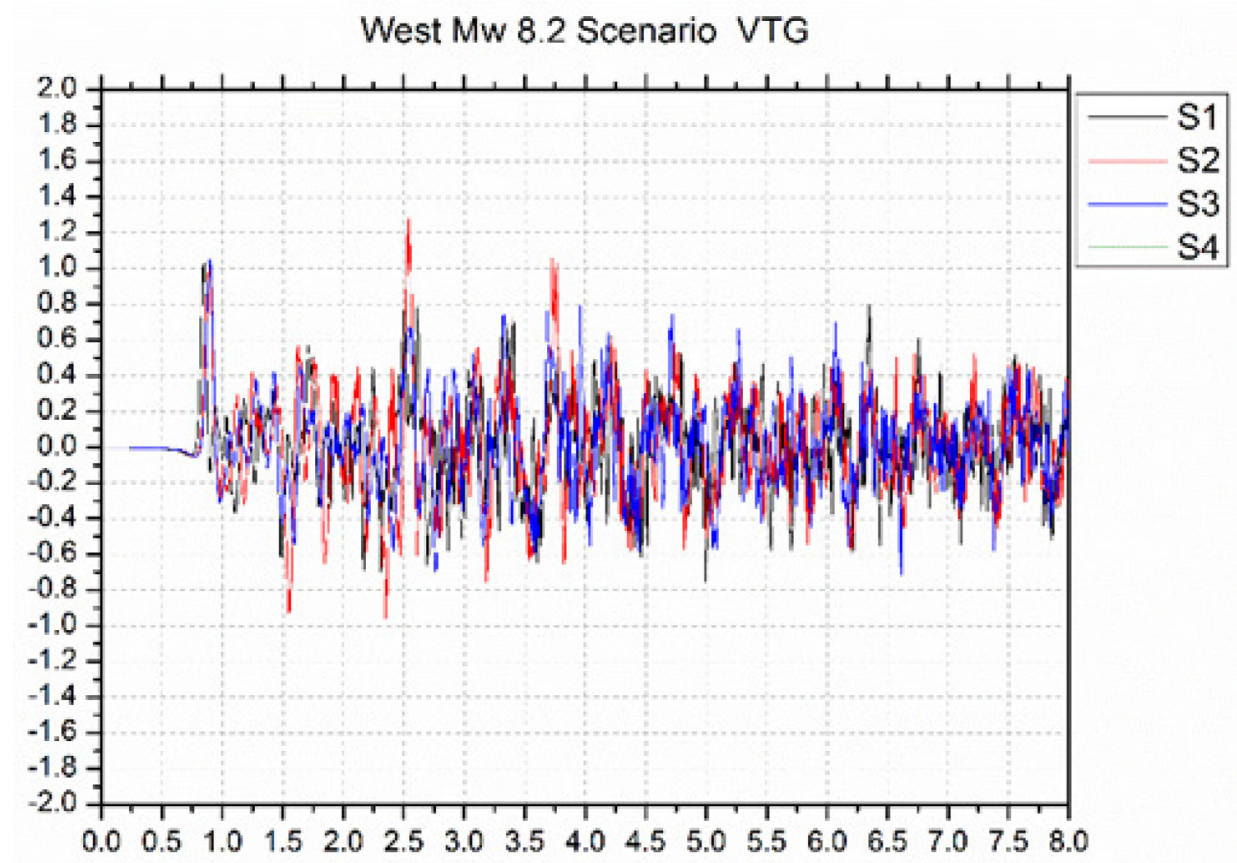

Fig. 8a. Synthetic waveforms at VTG from S1 to S4 (locations in Figure 9), maximum wave height of $1.2 \mathrm{~m}$. 


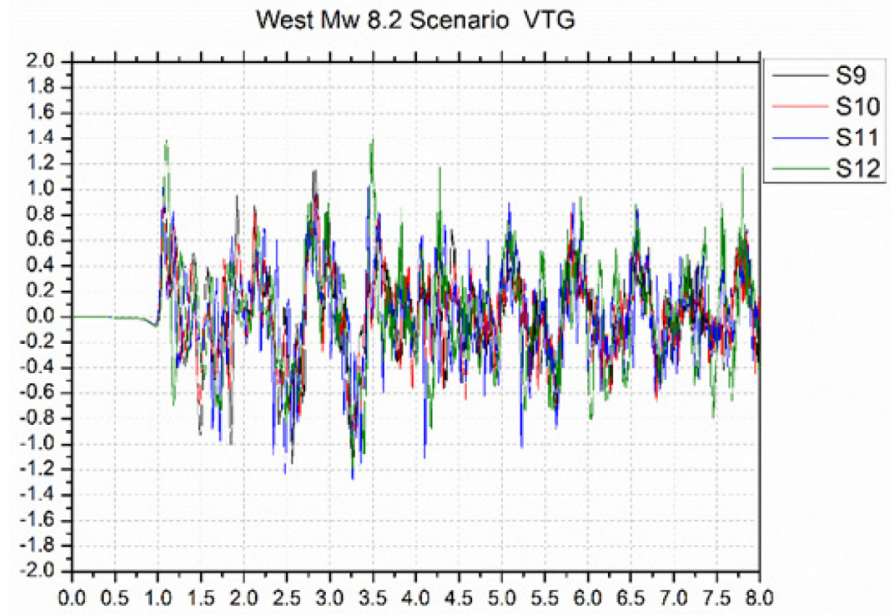

Fig. 8b. Synthetic waveforms at VTG from S9 to S12 (locations in Figure 9), maximum wave height of $1.4 \mathrm{~m}$.

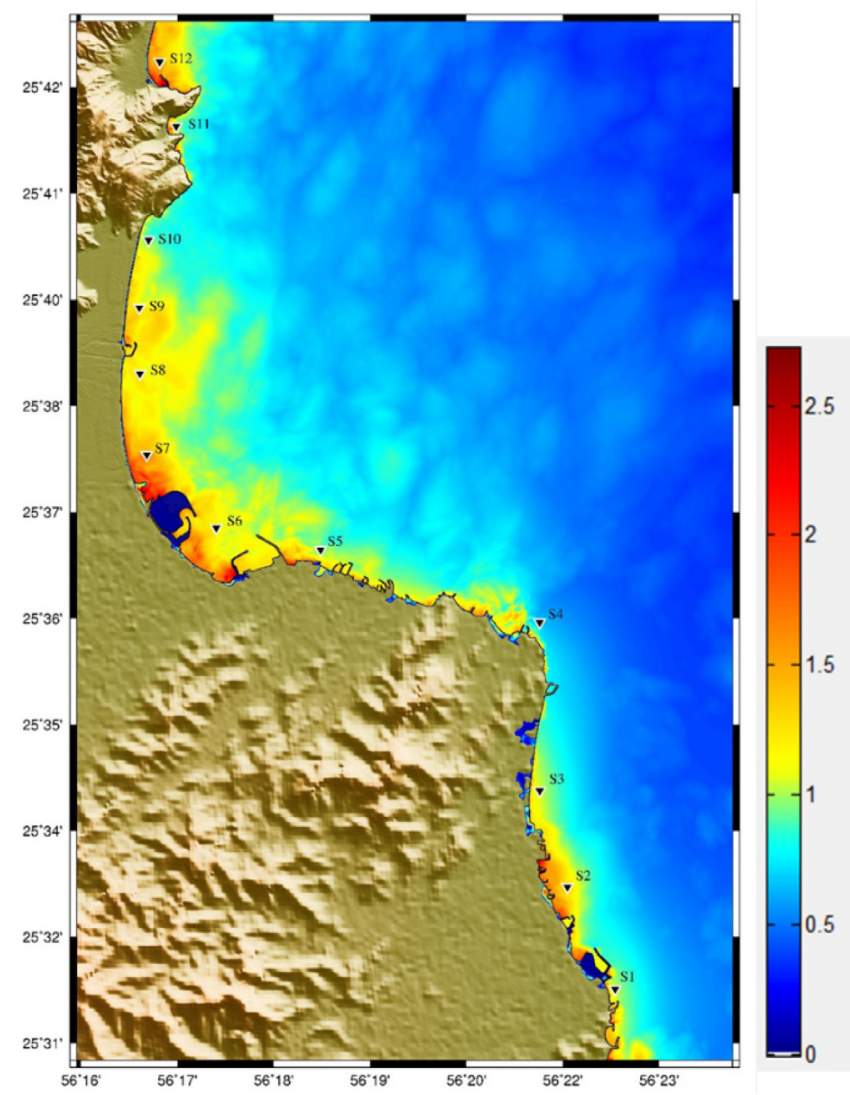

Fig. 9. Tsunami hazard map for Diba Oman with $5 \mathrm{~m}$ grid spacing representing maximum wave height and inundation in meters for Scenario two $\mathrm{M}_{\mathrm{w}}$ 8.2., also showing the locations of 12 virtual tide gauges (VTG). 


\section{Conclusions}

Deterministic tsunami hazard assessment for Diba coast shows a maximum run-up of $1.16 \mathrm{~m}$ and maximum flow depth of $1.37 \mathrm{~m}$ due to an earthquake of $\mathrm{Mw} 8.8$ from eastern Makran Subduction Zone. The run-up would be $2.57 \mathrm{~m}$ and the flow depth would be $2.34 \mathrm{~m}$ due to an earthquake scenario of Mw 8.2 from western Makran Subduction zone. The hazard from western Makran subduction would be higher than that of the eastern Makran subduction for even a lower magnitude due to close proximity to Diba coasts.

\section{References}

1. I.El-Hussain,A.Deif, k. Al-Jabri, S. Al-Hashmi, K. Al-Tobi, Y. Al-shigbi, M. AlSaifi, 2012. Nat. Hazard, 64:173-210(2012)

2. M. Heidarzadeh, M.D. Pirooz, N.H. Zaker, C.E. Synolakis. Pure Appl. Geophys. 165(11-12): 2045-2058(2008)

3. M. Mokhtari, I.A. Fard, K. Hessami , Natural Hazards 47(2):185-99. doi: 10/1007s11069-007-9208 (2008)

4. D. R. Burbidge, P.R. Cummins, R. Mleczko, H. Latief, M. Mokhtari, D. Natawidjaja, C.P. Rajendran, C. Thomas, Geoscience Australia professional opinion. No: 2009/11 (2009)

5. D.E. Byrne, L.R. Sykes, S.M. Davis, J Geophys Res97-B1: 449-478,(1992)

6. A. Deif, I. El-Hussain, J Geophys Eng 9: 773-783(2012)

7. A. Deif, I. El-Hussain, K. Al-Jabri, N. Toksoz, S. El-Hady, S. Al-Hashmi, K. Al-Tobi, Y. Al-shijbi, M. Al-Saifi, Arabian J. Geosciences, 6, 4947-4960(2013)

8. I. El-Hussain, R. Omira, A. Deif, Z. Al-Habsi, G. Al-Rawas, A.M.E. Mohamed, K. Al-Jabri, M. A. Baptista, Arabian J. Geosciences, 9: 1-14 (2016)

9. G. Hoffmann, K. Reicherter, T. Wiatr, C. Grützner, T. Rausch, Nat Hazards, (2013)

10. S. Neetu, I. Suresh, R. Shankar, B. Nagarajan, R. Sharma, S. Shenoi, A. Unnikrishnan, D. Sundar, Natural hazard, published online may (2011)

11. E. Okal, H.M. Fritz, C.E. Synolakis, P.E. Raad, Y. Al-Shijbi, M. Al-Saifi, Earthquake Spectra,22, S203-S218(2012)

12. M. Rodriguez, N. Chamo-Rooke, H. Hebert, M. Fournier, P. Puchon, Natural Hazards and Earth System Sciences, 13, 416-424 (2013)

13. GEBCO http://www.gebco.net/data_and_products/gridded_bathymetry_data/gebco_3 0 second $\operatorname{grid} /(2014)$

14. C. E. Synolakis, E.N. Bernard, V. V. Titov, U. Kânoğlu, F.I. Gonzalez, Pure and Applied Geophysics, 165(11-12), 2197-2228(2008)

15. R. Omira, L.M. Matias, M.A. Baptista, Pure App. Geophys.doi:10.1007/s00024-0161367-z(2016a) 